\title{
A new way to calculate productivity of five-spot pattern at high water cut stages
}

\author{
Hao-yu Wang ${ }^{1,2} \cdot$ Junjie $\mathrm{Li}^{3} \cdot$ Hailong Liu ${ }^{4}$
}

Received: 6 September 2018 / Accepted: 15 December 2018 / Published online: 20 December 2018

(c) The Author(s) 2018

\begin{abstract}
This paper presents a new way to calculate productivity of five-spot pattern at high water cut stages. In low permeability reservoirs, it is difficult for the reservoir fluid to flow, and the recovery factor is very low. Being based on the non-Darcy flow in low permeability reservoir, taking threshold pressure gradient into consideration, a new method to calculate the well pattern was built. This method is based on the two-parameter continuous model, and the method of flow line integrals and the numerical integration were used to build the productivity model. Productivity for the new method is validated by comparing with the actual data from field, and both the seepage theory and the reservoir engineering illustrate the correctness of the new method in this paper. The fracture length and pressure difference between the injection well and the production well have a significant effect on the productivity of the fractured five-point well pattern. The greater the length of the fracture is, the higher the productivity of the fractured five-point well pattern is. The greater the pressure difference is, the higher the productivity of the fractured five-point well pattern is.
\end{abstract}

Keywords Low-permeability reservoirs · Element analysis method · Flow tube integration method · Heterogeneity of remaining oil $\cdot$ Productivity

\section{Introduction}

Water flooding is an efficient method to maintain reservoir pressure, and it has been widely used to enhance oil recovery. Currently, most water-flooding reservoirs have been in a high water cut period in China. Due to the reservoir heterogeneity, different locations of the reservoir have different water flooding spread area, which results in that the distribution of remaining oil at high water cut stages are not the same.

Hailong Liu

478277608@qq.com

1 Key Laboratory of Exploration Technologies for Oil and Gas Resources (Yangtze University), Ministry of Education, Wuhan 430100, People's Republic of China

2 School of Geoscience, Yangtze University, Wuhan 430100, People's Republic of China

3 Shanghai Branch of CNOOC Ltd, Shanghai 200000, People's Republic of China

4 Research Institute of Petroleum Exploration and Development, SINOPEC, Beijing 100083, People's Republic of China
At present, several major oil companies in China face with the problem of low permeability reservoir development. However, because of low porosity and low permeability, low permeability reservoirs have some differences with middle and high permeability reservoirs. A large number of studies have shown that (Deng and Liu 2001; Zhu et al. 2010; Yang et al. 2011; Sun 2010): the reservoir fluid in low permeability reservoirs does not follow Darcy's law any more, and it is shown as a low-speed non Darcy percolation ( $\mathrm{Li}$ et al. 2008; Zhang and Wang 2011; Fu and Ge 2002; Zhu 2007; Yang et al. 2007). Previous classical reservoir engineering methods have some limitations in the application and guidance of low permeability reservoir development. It is mainly showed in the following aspects:

1. The seepage model is too idealized, and only singlephase flow is considered, and the distribution of remaining oil in the reservoir and the effect of water flooding are not fully considered;

2. The calculation unit is often concentrated in one injection and production unit, and there is still a certain gap with the actual low permeability reservoir development well network; 
3. The derivation process is complicated and inconvenient to calculate.

Therefore, it is necessary to establish an engineering calculation model for low permeability reservoir based on non-Darcy seepage.

At present, low permeability reservoirs are mainly exploited by area well pattern. In view of the productivity calculation of area well pattern, many researches have been done by predecessors. Using the principle of pressure superposition and the mirror inversion method, Luo et al. (2010) studied the pseudo-steady flow productivity and injection production pressure difference model was built for low permeability reservoirs with closed boundary. By combining the seepage characteristics of low permeability reservoirs and using the equivalent percolation resistance method, $\mathrm{Du}$ Dianfa et al. (2012) gives the expression of the area well network productivity. Based on the productivity formula of the area well network in the ultra-low permeability reservoir, $\mathrm{Xu}$ et al. (2014) used the superposition principle and the equivalent well diameter model to build the productivity expression for the joint area of horizontal well and straight well. He et al. (2009) adopt the flow pipe method to establish the production model of the low permeability rectangular reservoir fracturing straight well. Using the similarity principle of hydropower Zhao et al. (2008) derived the productivity model of different types of well pattern.

Previous studies are summarized in three aspects: starting pressure gradient model, productivity splitting model and quasi starting pressure gradient model. Based on the previous research results, this paper uses the streamline integration method (Munseok 2000; Higgins and Leighton 1961; Ji et al. 2008; He et al. 2009a, b), based on the non-Darcy flow and the two-parameter model, an area well network productivity model considering the starting pressure gradient is built, which makes the production calculation and the well network optimization closer to the actual production. By applying element analysis, an injection-producing unit of a fractured five-spot pattern is divided into four subunits, each of which is divided into three calculation units in accordance with streamline distribution characteristics. On this basis, the injection production pressure difference and the well spacing are analyzed. The start-up coefficient is introduced to evaluate the utilization degree of low permeability reservoir.

\section{Physical model for fractured five-spot patterns at high water cut stages}

The schematic illustration in Fig. 1a shows an injectionproducing unit of a fractured five-spot pattern. The fracture half-length of each injection well is the same which equals to $L_{\mathrm{fw}}$. The fracture half-length of production well equals to $L_{\mathrm{fo}}$. Well spacing and spacing of well array equal to $L_{1}$ and $L_{2}$, respectively. By applying element analysis, an injection-producing unit of a fractured five-spot pattern is divided into four SUs, each of which is divided into three CUs in accordance with streamline distribution characteristics. Therefore, an injection-producing unit of a fractured five-spot pattern is divided into 12 CUs totally, as shown in Fig. $1 b$.

The assumptions are as follows:

- The saturation distributed in the injection-producing unit is not uniform at the high water cut stage. Various SUs have different saturation. However, Saturation for a SU is the same.

- Before seeing water in the oil well, the permeability is constant;

- In an injection unit, the starting pressure gradient is constant;

- The two-phase unstable percolation occurs in the fluid flow in the stratum, and the fluid viscosity is constant.

- The effects of gravity and capillary forces are ignored;

- In the injection unit, no gas is dissolved or escaped.

- Fractures of injection well and production well have infinite conductivity

Productivity of an injection-production unit for a fracture five-spot pattern equals to the sum of productivities for all CUs. Method of productivity for every CU is introduced in the next part.

There are many methods for describing mathematical models of nonlinear seepage at present (Ruina and Xiaodong 2011; Baoquan et al. 2011; Xu et al. 2018), as shown in Table 1 . The seepage model in Table 1 is mainly divided into the proposed pressure gradient model, segmented model and continuous model. At present, the nonlinear seepage is mainly based on phenomenological method. The reason is that the classical Darcy's law cannot describe the percolation characteristics of the lowpermeability reservoirs. The low-permeability reservoirs have the starting pressure, boundary layer and micro-scale flow effects, and the starting pressure is not a constant which increases the difficulty and accuracy of describing the equation of motion of the true seepage law of lowpermeability reservoir fluids.

Where $v$ is the seepage velocity for a flow tube, sm/day; $\nabla p$ is the displacement pressure between the injection well and the production well, $\mathrm{MPa} ; k$ is the effective permeability for fluid flow, $10^{-3} \mu^{2} ; a_{1}, a_{2}, a, b$ are the model parameters and their values are related to the actual reservoir; $\mu$ is the fluid viscosity, $\mathrm{mPa} \mathrm{s}$; $G$ is the starting pressure gradient, $\mathrm{MPa} / \mathrm{m} ; L$ is the distance from injection well along the centerline for a flow tube, $\mathrm{m}$. 


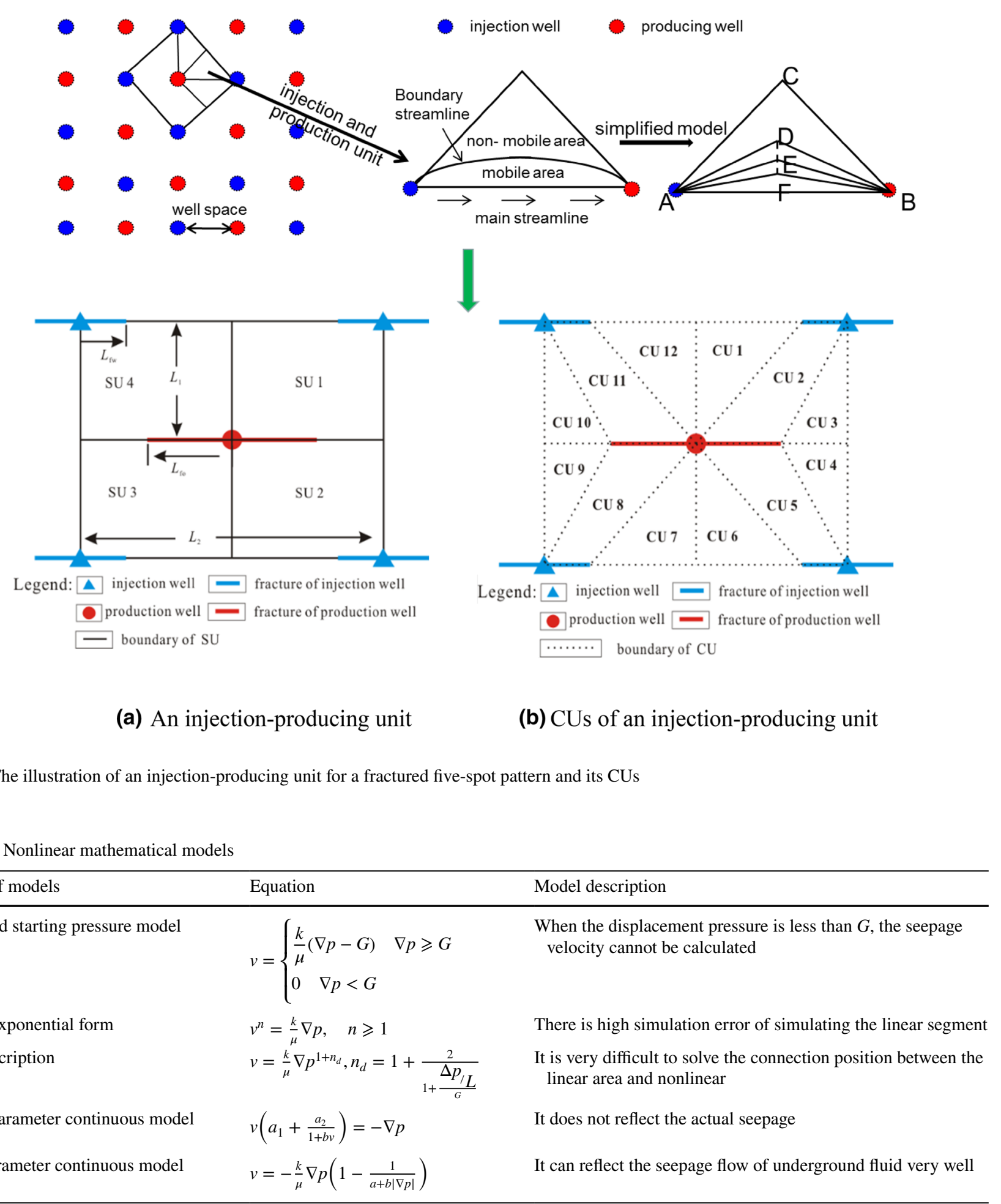

\section{Productivity for every CU}

The well pattern productivity equals to the sum of the production for all flow tubes which are distributed in the $\mathrm{CU}$. Therefore, it is necessary for the production well to calculate the production of a flow tube.
From Table 1, the two-parameter continuous model reflect the seepage flow of underground fluid well, and it is also very easy to get the two-parameter in this model, so this paper chooses the two-parameter continuous model as the basic seepage model to build the production model for the flow tube. 


\section{Production for a flow tube}

The injection unit interface diagram is shown in Fig. 2. By rewriting the two-parameter continuous model and taking the oil-water two-phase flow into consideration, the production of a cross-sectional of a flow tube is given by the following equation,

$q_{\mathrm{o}}=c \frac{k_{\mathrm{o}}\left(\bar{s}_{\mathrm{w}}\right)}{\mu_{\mathrm{o}}} A(\xi)\left(1-\frac{1}{a+b \frac{\mathrm{dp}_{\xi}}{\mathrm{d} \xi}}\right)$,

where $q_{\mathrm{o}}$ is the production of a single flow tube, $\mathrm{sm}^{3} /$ day; $c$ is unit conversion factors; $k_{\mathrm{o}}\left(\bar{s}_{\mathrm{w}}\right)$ is the effective permeability of oil, $10^{-3} \mu \mathrm{m}^{2} ; \bar{s}_{\mathrm{w}}$ is the average water saturation; $\mu_{\mathrm{o}}$ is the oil viscosity, $\mathrm{mPa} \mathrm{s} ; \xi$ is the distance between the injection well and the cross section, $\mathrm{m} ; A(\xi)$ is the cross-sectional area, $\mathrm{m}^{2} ; \mathrm{dp}_{\xi}$ is the displacement pressure of the cross section, $\mathrm{MPa} ; \lambda$ is the starting pressure gradient, $\mathrm{MPa} / \mathrm{m} ; a, b$ are the parameters of the model, the values are related to the actual reservoir.

Equation (1) can be rewritten as:

$\mathrm{dp}_{\xi}=\left(\frac{1-a}{2 b}+\frac{M}{2}+\frac{\sqrt{(a+1+M b)^{2}-4 a}}{2 b}\right) \mathrm{d} \xi$,

where $M=\frac{\Delta q}{\sum_{i=1}^{2} A\left(\xi_{i}\right)} \frac{\mu}{k}$.

Integrating of Eq. (2) over $\xi$, the production for a flow tube can be obtained, as the following:

$q_{\mathrm{o}}=c \frac{\frac{k_{\mathrm{o}}\left(\bar{s}_{\mathrm{w}}\right)}{\mu_{\mathrm{o}}}\left(P_{\mathrm{in}}-P_{\text {pro }}-\lambda l\right)}{\int_{l} \frac{d \xi}{A(\xi)}}$,

where $P_{\text {in }}$ is the injection well pressure, MPa; $P_{\text {pro }}$ is the production well pressure, $\mathrm{MPa} ; l$ is the length of a single flow tube, $\mathrm{m}$.

\section{Production for a triangular CU}

When the two phases of oil and water reach pseudo-steady state flow, the production of each triangular $\mathrm{CU}$ is the same. To simplify the model, this paper just takes the CU 1 as an example to calculate the production of a triangular $\mathrm{CU}$, which is shown in Fig. 3.
By rewriting the Eq. (3), the production of a single flow tube of CU 1 must meet:

$q_{\mathrm{o} 1}=c \frac{\frac{k_{\mathrm{o}}\left(\bar{s}_{\mathrm{w}}\right)}{\mu_{\mathrm{o}}}\left(P_{\mathrm{in}}-P_{\mathrm{pro}}-\lambda l_{1}\right)}{\int_{l_{1}} \frac{d \xi}{A(\xi)}}$,

where $l_{1}$ is the length of a single flow tube of CU $1, \mathrm{~m} . ; q_{\mathrm{o} 1}$ the production of a flow tube of $\mathrm{CU} 1, \mathrm{sm}^{3} /$ day.

In Fig. 3, the following relationship can be easily obtained:

$\frac{\alpha}{\beta}=\frac{\Delta \alpha}{\Delta \beta}=\frac{\alpha_{m}}{\beta_{m}}=n$,

$x_{i}=\frac{\omega d}{\sin (\alpha+\beta)} \sin \left[\frac{\alpha+\beta}{2}-(-1)^{i} \frac{\alpha-\beta}{2}\right], \quad i=1,2$,

$A_{i}(\xi)=2 h \xi_{i} \operatorname{tg}\left[\frac{\Delta \alpha+\Delta \beta}{4}-(-1)^{i} \frac{\Delta \alpha-\Delta \beta}{4}\right], r_{w} \leqslant \xi_{i} \leqslant x_{i}, \quad i=1,2$,

where $r_{w}$ is the well radius, $\mathrm{m} ; \alpha, \beta$ is the angle of the CU1 between the selected point of the main streamline from the production well and the injection well, respectively, ${ }^{\circ} ; \alpha_{m}$, $\beta_{m}$ is the angle of flow tube between the selected point of the main streamline from the production well and the injection well, respectively, ${ }^{\circ} ; \Delta \alpha, \Delta \beta$ is the angle increment of flow tube between the selected point of the main streamline from the production well and the injection well, respectively, ${ }^{\circ} ; n$ is the shape factor of $\mathrm{CU} 2$;

Substitute Eqs. (5)-(7) into Eq. (8), it can be obtained that:

$l_{1}=\sqrt{L_{1}^{2}+\left(\frac{L_{2}}{2}-x_{1}\right)^{2}} \frac{\left(\sin \alpha_{m}+\sin \beta_{m}\right)}{\sin \left(\alpha_{m}+\beta_{m}\right)}-r_{\mathrm{w}}$.

By the way, $A(\xi)$ is also can be obtained:

Substitute Eqs. (7)-(8) into Eq. (4), it can be obtained that:

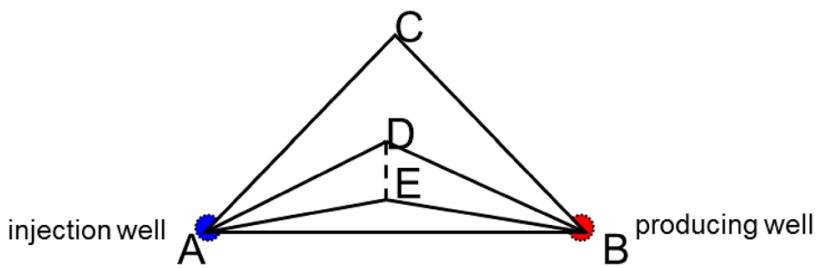

Fig. 3 The illustration of CU 1
Fig. 2 Single flow tube sketch diagram

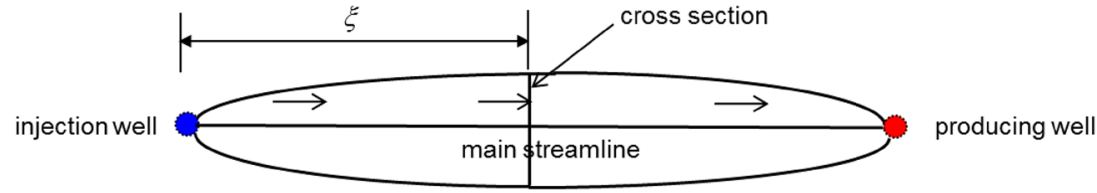




$$
q_{\mathrm{o} 1}=c \frac{\frac{k_{\mathrm{o}}\left(\bar{s}_{\mathrm{w}}\right)}{\mu_{\mathrm{o}}}\left(P_{\mathrm{in}}-P_{\mathrm{pro}}-\lambda\left(\sqrt{L_{1}^{2}+\left(\frac{L_{2}}{2}-x_{i}\right)^{2}} \frac{\left(\sin \alpha_{m}+\sin \beta_{m}\right)}{\sin \left(\alpha_{m}+\beta_{m}\right)}-r_{\mathrm{w}}\right)\right)}{\frac{1}{2 h \tan \left(\frac{\Delta \alpha}{2}\right)} \ln \left(\frac{\sqrt{L_{1}^{2}+\left(\frac{L_{2}}{2}-L_{\mathrm{fw}}\right)^{2}} \sin \beta_{m}}{\sin \left(\alpha_{m}+\beta_{m}\right) M}\right)+\frac{1}{2 h \tan \left(\frac{\Delta \beta}{2}\right)} \ln \left(\frac{\sqrt{L_{1}^{2}+\left(\frac{L_{2}}{2}-L_{\mathrm{fw}}\right)^{2}} \sin \alpha_{m}}{\sin \left(\alpha_{m}+\beta_{m}\right) M}\right)} .
$$

The production of CU 1 can be obtained:

where $l_{2}$ is the length of a single flow tube of CU $1, \mathrm{~m} ; q_{\mathrm{o} 2}$ the production of a flow tube of CU $1, \mathrm{sm}^{3} /$ day.

$$
\begin{aligned}
& Q_{\mathrm{o} 1}=\int_{0}^{\alpha} q_{\mathrm{o} 1} \mathrm{~d} \alpha \\
& =c \int_{0}^{\alpha} \frac{\frac{k_{\mathrm{o}}\left(\bar{s}_{\mathrm{w}}\right)}{\mu_{\mathrm{o}}}\left(P_{\mathrm{in}}-P_{\mathrm{pro}}-\lambda\left(\sqrt{L_{1}^{2}+\left(\frac{L_{2}}{2}-x_{i}\right)^{2}} \frac{\left(\sin \alpha_{m}+\sin \beta_{m}\right)}{\sin \left(\alpha_{m}+\beta_{m}\right)}-r_{\mathrm{w}}\right)\right)}{\frac{1}{2 h \tan \left(\frac{\Delta \alpha}{2}\right)} \ln \left(\frac{\sqrt{L_{1}^{2}+\left(\frac{L_{2}}{2}-L_{\mathrm{fw}}\right)^{2}} \sin \beta_{m}}{\sin \left(\alpha_{m}+\beta_{m}\right) M}\right)+\frac{1}{2 h \tan \left(\frac{\Delta \beta}{2}\right)} \ln \left(\frac{\sqrt{L_{1}^{2}+\left(\frac{L_{2}}{2}-L_{\mathrm{fw}}\right)^{2}} \sin \alpha_{m}}{\sin \left(\alpha_{m}+\beta_{m}\right) M}\right)} \mathrm{d} \alpha,
\end{aligned}
$$

where $Q_{\mathrm{o} 1}$ is the production of $\mathrm{CU} 1, \mathrm{sm}^{3} /$ day.

\section{Production for a quadrilateral CU}

When the two phases of oil and water reach pseudo-steady state flow, the production method for each quadrilateral CU is the same. To simplify the model, this paper just takes the $\mathrm{CU}$ 1 as an example to calculate the production of a triangular $\mathrm{CU}$, which is shown in Fig. 4.

By rewriting the Eq. (3), the production of a single flow tube of CU 2 must meet:

$q_{\mathrm{o} 2}=\frac{\frac{k_{\mathrm{o}}\left(\bar{s}_{\mathrm{w}}\right)}{\mu_{\mathrm{o}}}\left(P_{\mathrm{in}}-P_{\text {pro }}-\lambda l_{2}\right)}{\int_{l_{2}} \frac{d \xi}{A(\xi)}}$,
In Fig. 4, the following relationship can be easily obtained:

$l_{2}=\sqrt{0.5\left(L_{2}-L_{\mathrm{fw}}-L_{\mathrm{fo}}\right)}$,

$\frac{L_{\mathrm{fo}}}{L_{\mathrm{fw}}}=\frac{\Delta L_{\mathrm{fo}}}{\Delta L_{\mathrm{fw}}}=m$,

where $A^{\prime} F^{\prime}$ equals to $\Delta L_{\mathrm{fo}}, \mathrm{m} ; C^{\prime} E^{\prime}$ equals to $\Delta L_{\mathrm{fw}}, \mathrm{m} ; m$ is the shape factor of CU 2.

Substitute Eqs. (15)-(17) into Eq. (14), it can be obtained that:

$q_{\mathrm{o} 2}=c \frac{k_{\mathrm{o}}\left(\bar{s}_{\mathrm{w}}\right)}{\mu_{\mathrm{o}}}\left[\frac{\Delta q}{\Delta a} \frac{1}{2 m h} \ln \frac{x_{1}}{r_{\mathrm{w}}}+\frac{\Delta q}{\Delta a} \frac{1}{2 m h}\right]$.

The production of CU 2 can be obtained:
Fig. 4 The illustration of $\mathrm{CU} 2$ and its flow tube in the situation where $L_{\text {wf }} \neq L_{\text {wo }}$

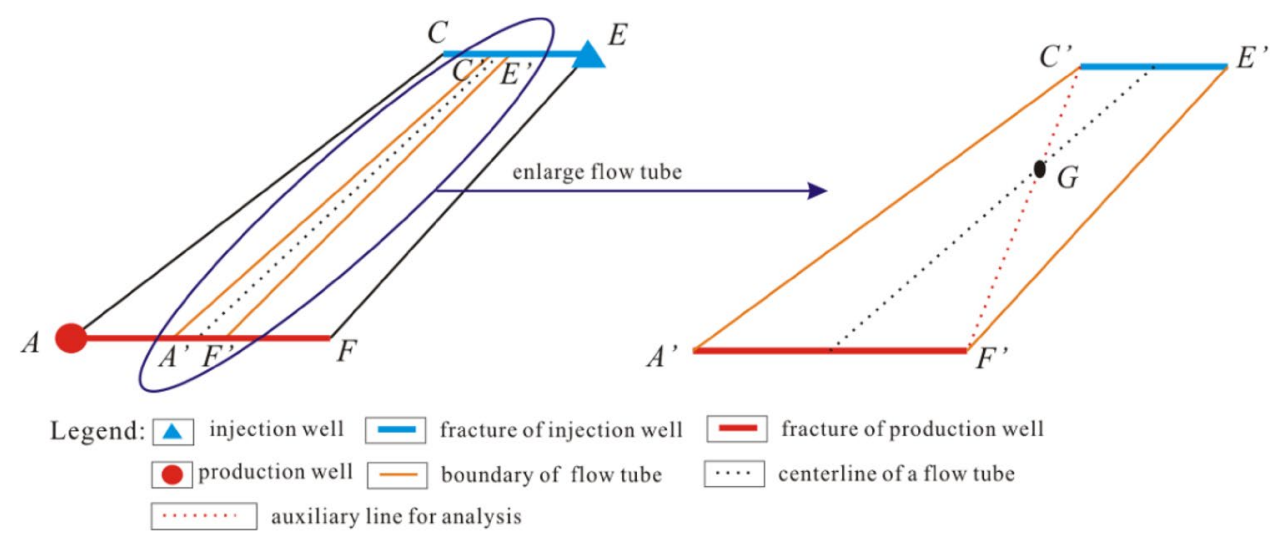




$$
\begin{aligned}
Q_{\mathrm{o} 2} & =\int_{0}^{\alpha} q_{\mathrm{o} 2} \mathrm{~d} \alpha \\
& =c \frac{k_{\mathrm{o}}\left(\bar{s}_{\mathrm{w}}\right)}{\mu_{\mathrm{o}}}\left[\int_{r_{\mathrm{w}}}^{x_{1}} \frac{\sqrt{\left(a+1+\frac{\Delta q}{\Delta a} \frac{\mu b}{k h \xi_{1}}\right)^{2}-4 a}}{2 b} \mathrm{~d} \xi_{1}+\int_{r_{\mathrm{w}}}^{x_{2}} \frac{\sqrt{\left(a+1+\frac{\Delta q}{\Delta a} \frac{\mu b}{n k h \xi_{2}}\right)^{2}-4 a}}{2 b} \mathrm{~d} \xi_{2}\right],
\end{aligned}
$$

where $Q_{\mathrm{o} 2}$ is the production of CU $2, \mathrm{sm}^{3} /$ day.

Above these two situation, the production for a five-spot pattern can be obtained:

$Q_{\mathrm{o}}=\sum_{i=1}^{12} Q_{\mathrm{o} i}$

\section{Transient productivity method for fractured five-spot patterns}

According to the material conservation theory, it can be obtained that:

$\bar{s}_{\mathrm{w} j}^{n+1}=\bar{s}_{\mathrm{w} j}^{n}+\frac{Q_{\mathrm{osj}} \Delta t B_{\mathrm{o}}}{V_{\phi j}}$,

where $j$ is the number of SU; $\bar{s}_{n j}$ and $\bar{s}_{n+1}$ are the average water saturation of SU $j$ at the time $t_{n}$ and $t_{n+1}$, respectively. $V_{\phi j}$ is the pore volume of $\mathrm{SU} j \cdot Q_{\mathrm{osj}}$ is the production of $\mathrm{SU}$ $j$ at the time $t_{n}, \mathrm{sm}^{3} /$ day, $\Delta t=t_{n+1}-t_{n}$.

So the $Q_{\text {osj }}(j=1,2,3$ or 4$)$ can be written as the following:

$Q_{\mathrm{os} 1}=\sum_{j=1}^{3} Q_{\mathrm{o} j}$

$Q_{\mathrm{os} 2}=\sum_{j=4}^{6} Q_{\mathrm{oj}}$

$Q_{\mathrm{os} 3}=\sum_{j=7}^{9} Q_{\mathrm{oj}}$

$Q_{\mathrm{os} 4}=\sum_{j=10}^{12} Q_{\mathrm{o} j}$
By combining the Eqs. (18)-(21), and by following the operation of 'six step method', the transient productivity of fractured five-spot patterns can be obtained.

The method is present as the following (Yao et al. 2014; Yoa and Wang 2004):

1. (1) The initial reservoir parameters and saturation for each SU are known;

2. (2) Calculate the production of every $\mathrm{CU}$ at the beginning moment using Eqs. (10) and (15);

3. (3) Calculate the production of every $\mathrm{SU}$ at the beginning moment using Eqs. (18)-(21);

4. (4) Calculate the production for fractured five-spot patterns at the beginning moment using Eq. (16);

5. (5) Calculate the saturation for each $\mathrm{SU}$ at the next moment using Eq. (17);

6. (6) Update the saturation for each $\mathrm{CU}$ in the steps (1), Repeat steps (2)-6, one can get the production for fractured five-spot patterns at the next moment; Finally, we get the transient productivity.

\section{Reservoir basic parameters and productivity method validation}

\section{Reservoir basic parameters}

The Lasa Xing oil field is located in the Changshu anticlinal structural belt in the Central Depression of the Songliao Basin, and it is also located in the most favorable area for oil production and oil storage in the Songliao basin. The sedimentary system is a large river-delta body, and the lithology is mainly fine sand and siltstone. The air permeability of the main oil layer is $0.5 \mu \mathrm{m}^{-2}$ or less, and the permeability of the thin sand layer is between 0.02 and $0.08 \mu \mathrm{m}^{-2}$, and the permeability of the off-sheet reservoir is between 0.001 and $0.05 \mu \mathrm{m}^{-2}$, which is an anticline structured reservoirs and also a low permeability reservoir. The Lasa Xing oil field is now in the high water cut stage. This paper takes the Lasa Xing oil field as an example to show the method of calculating productivity for five-spot well pattern.

The input value which are necessary for the model to calculating the productivity is shown in Table 2 . 
Table 2 The value of the input parameters

\begin{tabular}{llll}
\hline Parameters & Value & Parameters & Value \\
\hline Oil viscosity, $\mu_{\mathrm{o}}$ & $8.04 \mathrm{mPa} \mathrm{s}$ & Porosity, $\square$ & 0.204 \\
Injection pressure $P_{\mathrm{in}}$ & $21.696 \mathrm{MPa}$ & Production pressure, $P_{\text {pro }}$ & $9.6 \mathrm{MPa}$ \\
SU 1 permeability, $k_{1}$ & $39.24 \mathrm{mD}$ & SU 3 permeability, $k_{3}$ & $30.6 \mathrm{mD}$ \\
SU 2 permeability, $k_{2}$ & $36.12 \mathrm{mD}$ & SU 4 permeability, $k_{4}$ & $35.28 \mathrm{mD}$ \\
SU 1 water saturation, $s_{\mathrm{w} 1}$ & 0.78 & SU 3 water saturation, $s_{\mathrm{w} 3}$ & 0.66 \\
SU 2 water saturation, $s_{\mathrm{w} 2}$ & 0.72 & SU 4 water saturation, $s_{\mathrm{w} 4}$ & 0.684 \\
Reservoir thickness, $h$ & $16.8 \mathrm{~m}$ & Wellbore radius, $r_{\mathrm{w}}$ & $0.1 \mathrm{~m}$ \\
Injection well fracture length of, $L_{\mathrm{fw}}$ & $280 \mathrm{~m}$ & Well spacing, $L_{2}$ & $240 \mathrm{~m}$ \\
Production well fracture length of, $L_{\mathrm{fo}}$ & $240 \mathrm{~m}$ & Fracture width, $w_{\mathrm{f}}$ & $0.024 \mathrm{~m}$ \\
\hline
\end{tabular}

The starting pressure gradient is given as the following:

$\lambda=\varepsilon\left(\frac{k}{\mu_{\mathrm{w} n}^{S_{\mathrm{w} n}} \mu_{\mathrm{o}}^{1-S_{\mathrm{wn}}}}\right)^{-n}$,

where $\varepsilon$ and $n$ are regression coefficients, and the value of $\varepsilon$ and $n$ are given as 1.2116 and 0.9428 in this paper. $\mathrm{S}_{\mathrm{w} n}$ is the normalized water saturation, which can be obtained by the following:

$S_{\mathrm{w} n}=\frac{S_{\mathrm{w}}-S_{\mathrm{wc}}}{1-S_{\mathrm{wc}}-S_{\mathrm{or}}}$,

where $S_{\mathrm{wc}}$ is the irreducible water saturation and $S_{\mathrm{or}}$ is the residual oil saturation of the reservoir.

The relative permeability of water phase can be obtained using the Parker-Lenhard model, that is:

$k_{\mathrm{rW}}=\left(1-s_{\mathrm{o}}\right)^{0.5}\left\{1-\left[1-\left(1-s_{\mathrm{o}}\right)^{\frac{1}{m}}\right]^{m}\right\}^{2}$.

The relative permeability of oil phase can be obtained by using the Brooks-Corey-Burdine model, that is

$k_{\mathrm{ro}}=s_{\mathrm{o}}{ }^{0.5}\left[1-\left(1-s_{\mathrm{o}}\right)^{\frac{1}{m}}\right]^{2 m}$.

$k_{\mathrm{ro}}, k_{\mathrm{rw}}$ is the relative permeability of the oil phase and the water phase, respectively; $s_{0}$ is the oil saturation; $m$ is the fitting parameter.

\section{Productivity method validation}

Step 1 Input parameters.

Through the fracture construction design report and fracture monitoring data, the fracture parameters of the injection-production well, such as the length of the fracture, are obtained. It is noted that the fracture half-length of the injection well is $125 \mathrm{~m}$, and the fracture length of the production well is $114 \mathrm{~m}$, which is not equal, so the Eq. (19) is used to obtain the production for a quadrilateral CU.

Step 2 Saturation distribution.
The target block is produced from October 10 in 2012 to February 11 in 2015. Now select the production time period: October 10 in 2012 to February 10 in 2015. The producing time is 40 months, and the time step will be set to 1 month. Calculated 40 times. Substituting the known parameters into Eq. (21), the saturation distribution of the previous time step and the next time step can be obtained, that is:

$\begin{cases}\bar{s}_{\mathrm{w} 1}^{n+1}=\bar{s}_{\mathrm{w} 1}^{n}+3.25 & \left(\bar{s}_{\mathrm{w} 1}^{0}=0.62\right) \\ \bar{s}_{\mathrm{w} 2}^{n+1}=\bar{s}_{\mathrm{w} 2}^{n}+4.11 & \left(\bar{s}_{\mathrm{w} 2}^{0}=0.61\right) \\ \bar{s}_{\mathrm{w} 3}^{n+1}=\bar{s}_{\mathrm{w} 3}^{n}+2.94 & \left(\bar{s}_{\mathrm{w} 3}^{0}=0.57\right) \\ \bar{s}_{\mathrm{w} 4}^{n+1}=\bar{s}_{\mathrm{w} 4}^{n}+1.07 & \left(\bar{s}_{\mathrm{w} 4}^{0}=0.58\right) .\end{cases}$

Step 3 Starting pressure gradient.

The saturation obtained in step 2 is normalized and substituted into Eq. (22) to obtain the starting pressure gradient at different time steps, that is:

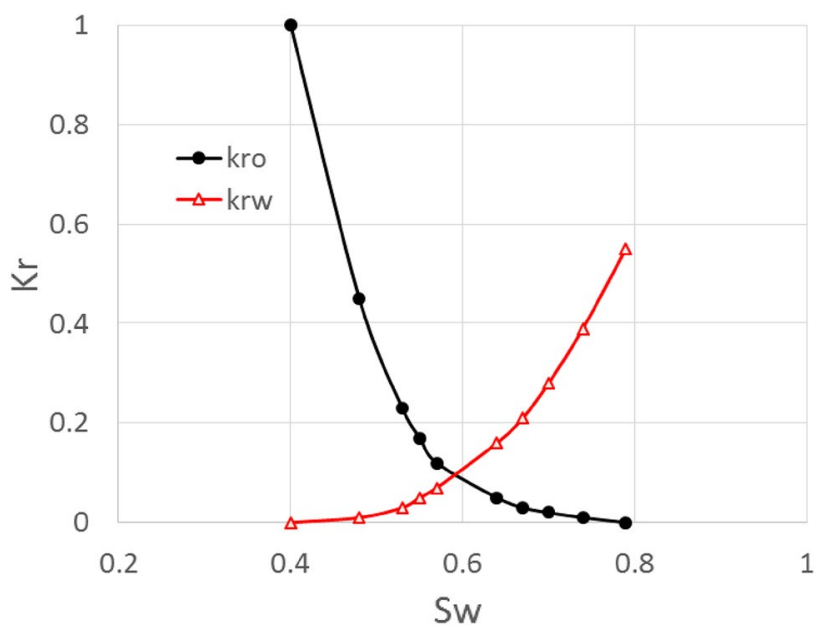

Fig. 5 Relative permeability curves 
Fig. 6 Calculating results between the new method and the actual data

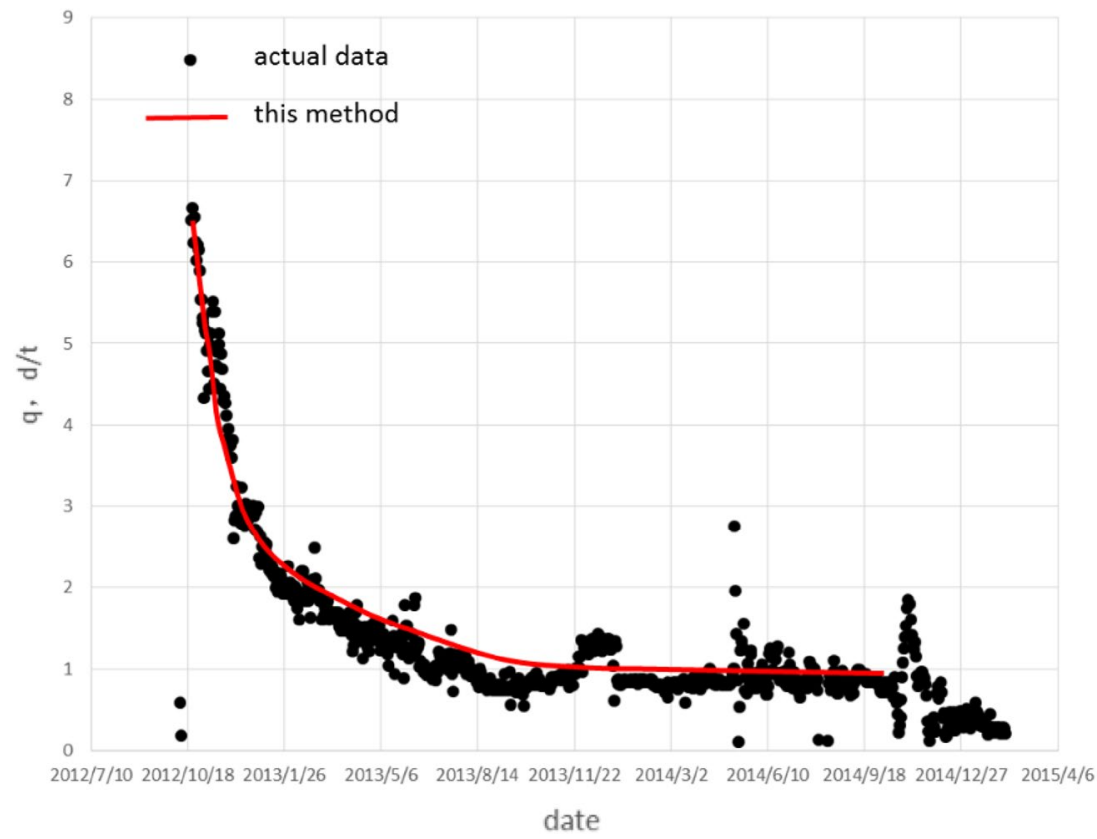

Table 3 calculation results between this paper solution and the reference solution

\begin{tabular}{llll}
\hline Well space & $\begin{array}{l}\text { Reference solu- } \\
\text { tion }\left(\mathrm{m}^{3} / \text { day }\right)\end{array}$ & $\begin{array}{l}\text { This paper solu- } \\
\text { tion }\left(\mathrm{m}^{3} / \text { day }\right)\end{array}$ & Relative error $(\%)$ \\
\hline 200 & 1.7492 & 1.7411 & 0.4680 \\
225 & 1.7202 & 1.7123 & 0.4631 \\
250 & 1.6951 & 1.6871 & 0.4727 \\
275 & 1.6729 & 1.6652 & 0.4652 \\
300 & 1.6532 & 1.6455 & 0.4674 \\
325 & 1.6355 & 1.6283 & 0.4437 \\
350 & 1.6194 & 1.6124 & 0.4375 \\
375 & 1.6048 & 1.5978 & 0.4334 \\
400 & 1.5913 & 1.5849 & 0.3997 \\
\hline
\end{tabular}

The phase-infiltration curve is obtained using the initial oil saturation and the combined formulas (24) and (25).

The relative permeability curves of the reservoir are shown in Fig. 5.

Step 4 The transient productivity can be obtained, which is shown in Fig. 6.

Through the 12 subdivided units, the capacity calculation formulas of the triangular injection unit and the quadrilateral injection unit can be obtained, that is:
$\left\{\begin{array}{l}Q_{\mathrm{o} 1}=\left.\frac{k_{\mathrm{o} 1}\left(s_{\mathrm{w} 1}^{0}\right)\left(8.01-0.372 G_{1}\right)}{7.296}\right|_{0} ^{31.4} \\ Q_{\mathrm{o} 2}=\left.\frac{k_{\mathrm{o} 2}\left(s_{\mathrm{w} 2}^{0}\right)\left(8.01-0.372 G_{2}\right)}{7.296}\right|_{0} ^{27.3} \\ Q_{\mathrm{o} 3}=\left.\frac{k_{\mathrm{o} 3}\left(s_{\mathrm{w} 3}^{0}\right)\left(8.01-0.372 G_{3}\right)}{7.296}\right|_{0} ^{39.5} \\ Q_{\mathrm{o} 4}=\left.\frac{k_{\mathrm{o} 4}\left(s_{\mathrm{w} 4}^{0}\right)\left(8.01-0.372 G_{4}\right)}{7.296}\right|_{0} ^{29.7} .\end{array}\right.$ 


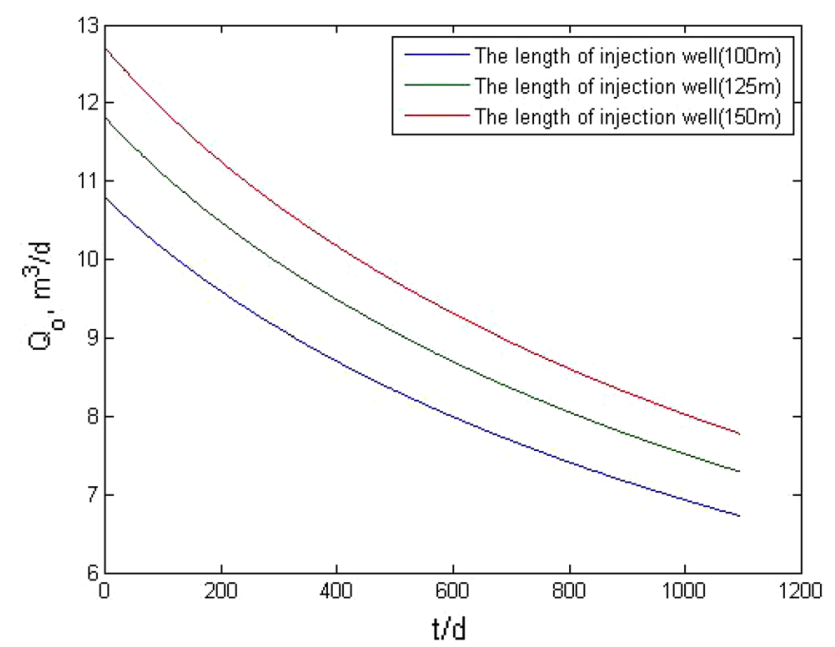

Fig. 8 Effects of fracture length of injection well on production

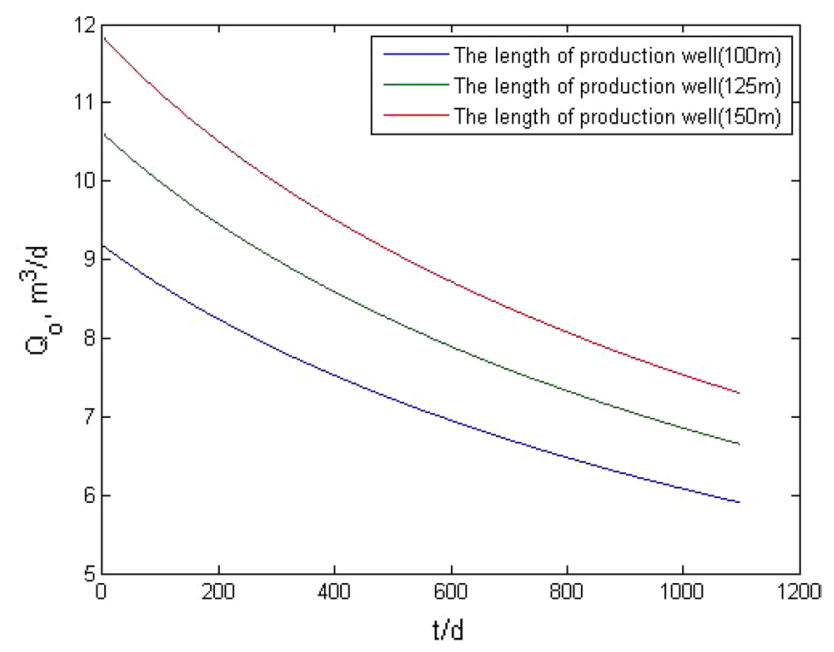

Fig. 9 Effects of fracture length of production well on production

The saturation obtained in the above step and the subunit average permeability inversely combined with the phase-infiltration curve are sequentially substituted into the corresponding sub-unit productivity model (28), and then using the iterative method, the transient productivity can be obtained, which is shown in Fig. 6.

Figure 6 shows the calculating results between the new method and the actual data. Figure 6 shows that the data of new method and the actual data have a quite good agreement, which means that the new method in this paper is reliable. Therefore, it is suitable to use this method to predict the transient productivity of five-spot patterns.

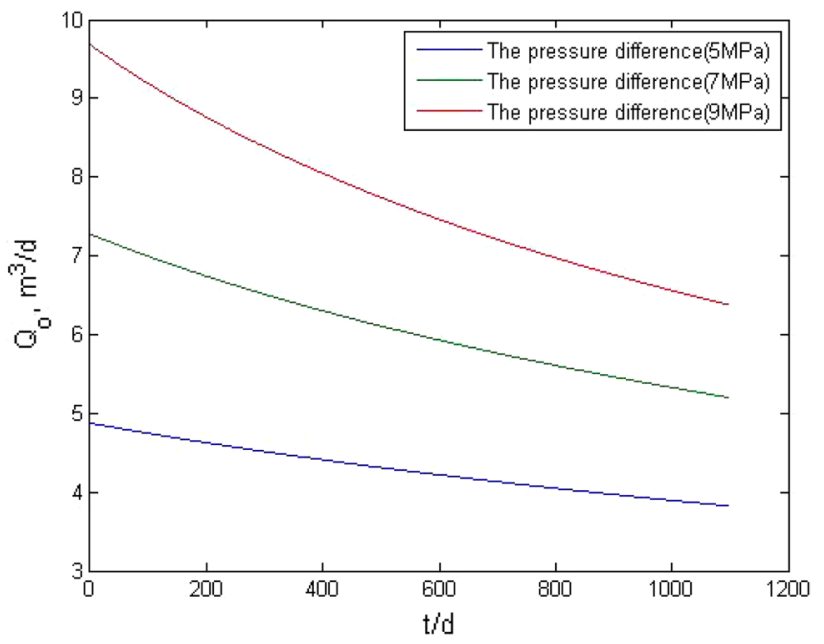

Fig. 10 Effects of pressure difference between injection well and production well on production

Figure 7 shows that it takes only $21.282 \mathrm{~s}$ to run the program of transient productivity prediction for a fractured fivespot pattern once, when the computer's processor model is Intel(R) Core(TM) i7-6700 CPU @3.4 GHz.

When $\lambda$ approaches zero, it becomes Darcy's seepage. The pressure difference between the production well and the injection well is $15 \mathrm{MPa}$, and the permeability is $0.033 \mathrm{mD}$, and the thickness of the oil layer is $5 \mathrm{~m}$, and the viscosity is $5 \mathrm{mPa} \mathrm{s}$, and the radius of wellbore is $0.1 \mathrm{~m}$. Calculate the single well output of the deduced five-point well network (this paper solution) and compare it with the Muskat (1937) calculation solution (reference solution), and the calculation results comparing between this paper solution and the reference solution is shown in Table 3 . Table 3 shows that the relative error is within $0.5 \%$, which shows the method in this paper is feasible and accurate.

Both the seepage theory and the reservoir engineering illustrate the correctness of the new method in this paper.

\section{Sensitivity analysis}

In this section, using the single factor variable principle, the impacts of some relevant parameters on the transient productivity of five-spot patterns are analyzed. The relevant parameters are shown in Table 2.

Figures 8 and 9 illustrate the impacts of fracture length on production and cumulative production for a fractured five-spot pattern. Seen from Figs. 8 and 9, the length of fracture has a significant effect on productivity or cumulative production for fracture five-spot patterns. The bigger the fracture length is, the more the production rate will be. From the analysis of flow regime, the flow regime in the area of CU 2, CU 4, CU 6 and CU 8 is linear flow. The 
flow regime in other CUs is radial flow. The bigger the fracture length, the bigger the area of CU 2, CU 4, CU 6 and CU 8 will be. Therefore, the flow resistance for a fractured five-spot pattern will be small and the productivity rate will be larger, when the fracture is longer.

Figure 10 shows the impacts of pressure difference between injection well and production well on production. Seen from Fig. 10, the bigger the pressure difference is, the more the productivity rate will be.

\section{Conclusions}

Using the methods of elemental analysis and flow tube integration, a new productivity of predicting five-spot well pattern is built, and this new method takes the remaining oil heterogeneity into account. This new method can accurately predict the productivity of the five-point model of fractured well in high water cut.

The fracture length and pressure difference between the injection well and the production well have a significant effect on the productivity of the fractured five-point well pattern. The greater the length of the fracture is, the higher the productivity of the fractured five-point well pattern is. The greater the pressure difference is, the higher the productivity of the fractured five-point well pattern is.

Acknowledgements This work was supported the State Energy Center for Shale Oil Research and Development.

\section{Compliance with ethical standards}

Conflict of interest The authors declare no conflicts of interest regarding the publication of this paper.

Open Access This article is distributed under the terms of the Creative Commons Attribution 4.0 International License (http://creativeco mmons.org/licenses/by/4.0/), which permits unrestricted use, distribution, and reproduction in any medium, provided you give appropriate credit to the original author(s) and the source, provide a link to the Creative Commons license, and indicate if changes were made.

\section{References}

Deng Y-E, Liu C-Q (2001) Mathematical model of nonlinear flow law in low permeability porous media and its application. Acta Pet Sin 22(4):72-76

Du Dianfa HJ, Dong-dong L et al (2012) Deliverability formulas for vertical-horizontal well pattern in low permeability oil reservoir. Pet Geol Recovery Effic 19(2):64-68

$\mathrm{Fu} \mathrm{C}, \mathrm{Ge} \mathrm{J}$ (2002) The discussion of nonlinear flow theory in low permeability reservoir. Xinjiang Pet Geol 23(4):317-320

He Y, Yang Z, Liu X et al (2009a) The productivity calculation for well pattern of low permeability reservoir considering threshold pressure gradient. J Southwest Pet Univ (Sci Technol Ed) 31(3):163-167

He Y, Yang Z, Xiong S (2009b) Research on rectangular pattern productivity calculation in low permeability reservoir. DPT 32(1):46-49

Higgins RV, Leighton AJ (1961) Performance of five- -spot water flood in stratified reservoirs using streamlines. In: Annual meeting of rocky mountain petroleum engineers of AIME, 26-27 May, Farmington, New Mexico. Society of Petroleum Engineers

Ji B, Li L, Wang C (2008) The calculation method of non-Darcy flow in low permeability reservoir area net oil production wells. Acta Pet Sin 29(2):230-255

Li S, Cheng L, Li X et al (2008) The study of nonlinear flow model in ultra-low permeability reservoirs. Pet Explor Dev 35(5):606-612

Luo W, Wang X, Chen J et al (2010) A new method for rapid productivity estimation of 5-spot well pattern. Pet Explor Dev 37(6):726-731

Munseok B (2000) A hybrid stream-tube simulator using a semi-analytical method. In: SPE Annual Technical Conference and Exhibition, 1-4 October, Dallas, Texas. Society of Petroleum Engineers

Muskat M (1937) The flow of homogeneous fluids through media. McGraw-Hill, New York

Ruina S, Xiaodong W et al (2011) The study of pressure disturbance propagation law in low permeability reservoir. Spec Reserv 18(4):80-82

Sun J (2010) Threshold pressure gradient study on non-Newtonian flow of heavy oil reservoirs in Shengli oilfield. Pet Geol Recovery Effic 17(6):74-77

Xu Q, Yu J, Jiang W et al (2014) A new method of predicting productivity of combined fractured horizontal well and vertical well for ultra-low permeability reservoir. Sci Technol Eng 14(18):30-34

$\mathrm{Xu} J$ et al (2018) Transient pressure behavior for dual porosity low permeability reservoir based on modified darcys equation. Society of Petroleum Engineers, pp 2789-2798

Yang Q, Yang Z, Wang Y et al (2007) The study of percolation theory in ultra-low permeability reservoir. Drill Prod Technol 30(6):52-54

Yang R, Jiang R, Liu S (2011) De-monstration of essentiality of considering nonlinear flow in low permeability reservoir. Fault Block Oil Gas Field 18(4):493-497

Yao H, Wang J (2014) Square-mean asymptotically almost periodic solutions to a class of stochastic integro-differential equations. $\mathrm{J}$ Harbin Univ Sci Technol 19(6):118-222

Yao H, Bu X, Song X (2014) Exponentiallyy mild asymptotically almost automorphic solutions for a class of differential equations. J Harbin Univ Sci Technol 19(5):23-25

Zeng B, Cheng L, Li C (2011) Low velocity non-linear flow in low permeability reservoir. J Pet Sci Eng 80(1):1-6

Zhang D, Wang Z et al (2011) The experimental study of the starting and smallest pressure gradient in low permeability reservoir. Xinjiang Pet Geol 29(1):106-109

Zhao C, Li P, Guo Z et al (2008) Study on calculation method of staggered pattern deliverability. Spec Oil Gas Reserv 15(6):67-72

Zhu S (2007) The study of pressure propagation in low permeability reservoirs. Xinjiang Pet Geol 28(1):85-87

Zhu W, Liu J, Song H et al (2010) Calculation of effective startup degree of non-Darcy flow in low or ultra-low permeability reservoirs. Acta Pet Sin 31(3):452-457

Publisher's Note Springer Nature remains neutral with regard to jurisdictional claims in published maps and institutional affiliations. 